\title{
Article \\ Topical Steroid Damaged Face: A Cross-Sectional Study from Saudi Arabia
}

\author{
Mahdi Al Dhafiri ${ }^{1, *}$, Alaa Baqer Alali ${ }^{2}$, Zuhur Ali Alghanem ${ }^{2}$, Zahraa Wasel Alsaleh ${ }^{2}$, \\ Eman Abdulrahman Boushel ${ }^{2}$, Zahraa Baqer Alali ${ }^{2}$ and Aeshah Adel Alnajjar ${ }^{2}$ \\ 1 Department of Dermatology, College of Medicine, King Faisal University, Al-Ahsa 31982, \\ Eastern Province, Saudi Arabia \\ 2 College of Medicine, King Faisal University, Al-Ahsa 31982, Eastern Province, Saudi Arabia; \\ alaaalali928@gmail.com (A.B.A.); zuhuralghanem@gmail.com (Z.A.A.); zahraawasel17@gmail.com (Z.W.A.); \\ eman-5006@hotmail.com (E.A.B.); zhrzhr13579@gmail.com (Z.B.A.); aishadel1999@gmail.com (A.A.A.) \\ * Correspondence: maldhafiri@kfu.edu.sa or mahdi056@hotmail.com
}

Citation: Al Dhafiri, M.; Alali, A.B.; Alghanem, Z.A.; Alsaleh, Z.W.; Boushel, E.A.; Alali, Z.B.; Alnajjar, A.A. Topical Steroid Damaged Face: A Cross-Sectional Study from Saudi Arabia. Clin. Pract. 2022, 12, 140-146. https://doi.org/10.3390/ clinpract12010018

Academic Editor: Luca Testarelli

Received: 9 January 2022

Accepted: 15 February 2022

Published: 21 February 2022

Publisher's Note: MDPI stays neutral with regard to jurisdictional claims in published maps and institutional affiliations.

Copyright: (c) 2022 by the authors. Licensee MDPI, Basel, Switzerland. This article is an open access article distributed under the terms and conditions of the Creative Commons Attribution (CC BY) license (https:/ / creativecommons.org/licenses/by/ $4.0 /)$.

\begin{abstract}
Corticosteroids are one of the anti-inflammatory drugs that are used widely by dermatologists. Significant local adverse effects can happen if topical corticosteroids (TCs) are used incorrectly. This study aimed to assess the prevalence of facial TCs misuse and its adverse effects. This was cross-sectional research: a self-reported questionnaire was distributed among a population of Saudi Arabians aged 16 years and above who were using TCs consecutively. Statistical analysis was performed using SPSS version 26. A total of 611 participants were enrolled in the survey: 401 (65.6\%) were university graduates, while $187(30.6 \%)$ were below high school level of education. The number of participants using TCs was 279 (45.7\%), while 332 (54.3\%) did not use steroids topically. The most used TCs were Mometasone furoate $0.1 \%$ cream (18.2\%), followed by Fusidic acid/Betamethasone cream (16.7\%). A total of 46 reported facial TCs' side effects. Peeling (52.2\%) was the most reported side effect, followed by redness $(41.3 \%)$. In conclusion, the use of facial TCs among the Saudi population is not uncommon (16.5\%). A large population are not aware of the side effects of the unsupervised use of TCs. An effort should be made to increase awareness of the adverse effects of TCs.
\end{abstract}

Keywords: topical corticosteroid; face; side effects; topical steroid damaged face

\section{Introduction}

In 1950, Philip Hench, Edward Kendall, and Tadeus Reichstein discovered the corticosteroid hormone [1]. Corticosteroids are a type of anti-inflammatory drug used in many specialties of medicine [2].

Topical corticosteroid is the synthetic form of natural corticosteroid which is synthesized in the adrenal cortex [3]. Topical corticosteroids are widely used by dermatologists and are highly effective in treating a variety of dermatological disorders. Topical corticosteroids (TCs) have a rapid effect in controlling dermatologic-inflammatory conditions due to their anti-inflammatory, anti-pruritic, and immunosuppressive effects on the skin [4]. There are different potencies of TCs ranging from mild to very potent. They are used over different body parts, including the face. Different dermatologic conditions are treated with TCs, including atopic dermatitis and psoriasis [5]. However, the side effects of steroids are unneglectable; they are ranging from mild to very severe depending on the area exposed to the TCs, period, and frequency of usage. Side effects are notable on soft, sensitive areas of the body with a high rate of transcutaneous absorption, such as the face. These adverse effects can include acne, telangiectasia, steroids rosacea, and hyper/hypopigmentation. The risk of these adverse effects increases with the long-term use of TCs [6]. Topical steroid damaged face (TSDF) was a newly described phenomenon in 2008, which is characterized by a group of symptoms induced by the prolonged, unsupervised usage of TCs on the face, 
regardless of the potency [6]. In this study, we aimed to assess the prevalence of TSDF among the population of Saudi Arabia and the associated adverse effects.

\section{Materials and Methods}

A community-based, cross-sectional study was conducted. A validated self-report questionnaire was distributed among participants to assess the adverse side effects of using facial TCs. The inclusion criteria were: (1) aged 16 years or above; (2) from Saudi Arabia; (3) male or female. The study proposal was ethically approved by the ethical committee of the scientific research committee at King Fahad Hofuf Hospital. Data collection was conducted by an online questionnaire using Google Forms. The questionnaire was validated after being designed by two expert consultant dermatologists. The next step included a pilot study through distributing the questionnaire to over 25 participants. Then, this process was followed by cleaning the collected data to reduce the risk of error, using principal components analysis, checking the internal consistency, and revising the survey as a final stage. The validated questionnaire was distributed by social media to the Saudi Arabian population. We had volunteers from each region who ensured that the questionnaire was delivered equally to all Saudi regions. The participants had given their consent to participate in the study before filling out the questionnaire. The questionnaire included the demographic data of the participants (age, gender, nationality, place of residence, marital status, education, and employment status). Then, it was followed by questions about the usage of TCs.

The population aged 16 and above who live in Saudi Arabia are 25,828,206, depending on the data available in the General Authority for Statistics of Saudi Arabia [7]. The sample size was calculated using this formula by $n=\mathrm{z} 2 \mathrm{pq} \backslash \mathrm{d} 2$. The confidence level was $95 \%$, the estimated proportion was $50 \%$, with a $5 \%$ level of precision. The minimum sample size was calculated to be 385 . However, more participants were included to ensure accuracy.

Data analysis was performed after data were extracted. It was revised, coded, and fed to statistical software IBM SPSS version 22 (SPSS, Inc. Chicago, IL, USA). All statistical analysis was conducted using two-tailed tests. A $p$-value less than 0.05 was statistically significant. Descriptive analysis based on frequency and percent distribution was performed for all variables, including participants' socio-demographic data, facial TCs use, types of used steroids, frequency of use, causes of use, TCs complications, and their satisfaction regarding used topical facial steroids. Cross tabulation was used to assess the distribution of facial TCs use according to their socio-demographic data. Relations were tested using Pearson's chi-square test and exact probability test for small frequency distributions.

\section{Results}

A total of 611 participants fulfilling the inclusion criteria completed the study questionnaire. The participants ranged from 16 to 67 years, with a mean age of $29.1 \pm 11.6$ years old. An exact number of $494(80.9 \%)$ participants were female. As for educational level, $401(65.6 \%)$ were university graduates, $187(30.6 \%)$ were high school graduates, and $(22.3 \%)$ were below high school. A total of 267 (43.7\%) respondents were students, $136(22.3 \%)$ had governmental jobs, and $160(26.2 \%)$ were not employed. Among participants, 62 (13.7\%) were physicians, $22(4.9 \%)$ were nurses, and $9(2 \%)$ were pharmacists. As for the prevalence of using facial steroids, 279 (45.7\%) study participants used TCs, while 332 (54.3\%) did not use TCs.

The most used type of TCs were Mometasone furoate $0.1 \%$ cream $(18.2 \%)$, followed by Fusidic acid/betamethasone cream $(16.7 \%)$, Hydrocortisone $1 \%$ cream $(4.4 \%)$, and Betamethasone valerate $0.1 \%$ cream $(0.8 \%)$. A total of $41.6 \%$ of the facial topical steroids users applied it to cheeks, while $21.5 \%$ used TCs on the forehead, $21.1 \%$ applied TCs around the mouth, $3.9 \%$ around their eyes, while $30.5 \%$ applied TCs for the whole face. Regarding the causes of using TCs, $45.9 \%$ of the users used for acne, followed by $30.5 \%$ for eczema/dermatitis, $14 \%$ used TCs to lighten their skin, $5 \%$ for freckles, and $5 \%$ for psoriasis. Regarding the frequency of using TCs, $35.1 \%$ applied TCs once daily, $16.1 \%$ applied steroids 
twice daily, and 7.2\% applied every 2 weeks. Exactly $44.1 \%$ of TCs users had the cream form, while $52 \%$ had ointment, and $3.9 \%$ used other forms. Using TCs for 1-2 months was reported among 38\% of the users, while $42.3 \%$ used topical steroids for more than 9 months. An exact number of 102 (36.6\%) participants who used the TCs reported still using it (Table 1).

Table 1. Distribution of topical corticosteroids use among participants.

\begin{tabular}{|c|c|c|}
\hline Topical Steroids Use Data & No (279) & $\%$ \\
\hline \multicolumn{3}{|l|}{ Used topical cortisone } \\
\hline None & 332 & $54.3 \%$ \\
\hline Mometasone & 111 & $18.2 \%$ \\
\hline Fusidic acid/betamethasone & 102 & $16.7 \%$ \\
\hline Others & 34 & $5.6 \%$ \\
\hline Hydrocortisone & 27 & $4.4 \%$ \\
\hline Betamethasone & 5 & $0.8 \%$ \\
\hline \multicolumn{3}{|c|}{ In which part of the face is topical cortisone used? } \\
\hline Cheeks & 116 & $41.6 \%$ \\
\hline All face & 85 & $30.5 \%$ \\
\hline Forehead & 60 & $21.5 \%$ \\
\hline Others & 60 & $21.5 \%$ \\
\hline Peri-oral & 59 & $21.1 \%$ \\
\hline Around the eyes & 11 & $3.9 \%$ \\
\hline \multicolumn{3}{|l|}{ Causes of using local CS } \\
\hline Acne & 128 & $45.9 \%$ \\
\hline Eczema \& dermatitis & 85 & $30.5 \%$ \\
\hline Others & 73 & $26.2 \%$ \\
\hline To lighten the skin & 39 & $14.0 \%$ \\
\hline Freckles & 14 & $5.0 \%$ \\
\hline Psoriasis & 14 & $5.0 \%$ \\
\hline \multicolumn{3}{|c|}{ How often do you apply topical cortisone? } \\
\hline 2 times / daily & 45 & $16.1 \%$ \\
\hline 1 time/daily & 98 & $35.1 \%$ \\
\hline Every 2 days & 13 & $4.7 \%$ \\
\hline Every 3 days & 13 & $4.7 \%$ \\
\hline Every week & 9 & $3.2 \%$ \\
\hline Every 2 weeks & 20 & $7.2 \%$ \\
\hline Others & 81 & $29.0 \%$ \\
\hline \multicolumn{3}{|l|}{ Type of topical cortisone used } \\
\hline Cream & 123 & $44.1 \%$ \\
\hline Ointment & 145 & $52.0 \%$ \\
\hline Others & 11 & $3.9 \%$ \\
\hline \multicolumn{3}{|c|}{ How long have you used topical cortisone on the face? } \\
\hline $1-2$ months & 106 & $38.0 \%$ \\
\hline $2-3$ months & 29 & $10.4 \%$ \\
\hline $3-6$ months & 18 & $6.5 \%$ \\
\hline $6-9$ months & 8 & $2.9 \%$ \\
\hline$>9$ months & 118 & $42.3 \%$ \\
\hline \multicolumn{3}{|c|}{ Still using topical cortisone on the face? } \\
\hline Yes & 102 & $36.6 \%$ \\
\hline No & 177 & $63.4 \%$ \\
\hline
\end{tabular}

Nevertheless, 154 (55.2\%) users had facial TCs based on a doctor's prescription. Among those who used unprescribed TCs, family \& friends were the main source of advice to use $(41.6 \%)$, followed by pharmacists $(25.6 \%)$, social media $(18.4 \%)$, and books (5.6\%). Only $77(27.6 \%)$ TCs users followed up with a dermatologist to note the effect of using TCs on the face. Side effects due to the use of facial TCs were reported among 
$46(16.5 \%)$ participants. The most reported side effects were peeling $(52.2 \%)$, followed by redness $(41.3 \%)$, dryness $(23.9 \%)$, skin color change $(21.7 \%)$, irritation $(19.6 \%)$, acne-like rash $(10.9 \%)$, and itching $(10.9 \%)$. A burning sensation was one of the least reported side effects $(6.5 \%)$, along with skin stretch marks (2.2\%). An exact number of $108(38.7 \%) \mathrm{knew}$ the side effects of using TCs, and 23 (50\%) of those with side effects reported they would return to use TCs if the side effects improved (Table 2).

Table 2. Distribution of topical corticosteroids prescribed use and its complications participants.

\begin{tabular}{|c|c|c|}
\hline Topical Steroid Prescription \& Complications & No (279) & $\%$ \\
\hline \multicolumn{3}{|c|}{ Used topical cortisone on the face based on a doctor's prescription? } \\
\hline Yes & 154 & $55.2 \%$ \\
\hline No & 125 & $44.8 \%$ \\
\hline \multicolumn{3}{|c|}{ If no, what is the source of your information? $(n=125)$} \\
\hline Family/friends & 52 & $41.6 \%$ \\
\hline Pharmacist & 32 & $25.6 \%$ \\
\hline Social media & 23 & $18.4 \%$ \\
\hline Books & 7 & $5.6 \%$ \\
\hline Others & 11 & $8.8 \%$ \\
\hline \multicolumn{3}{|c|}{ Follow up with a dermatologist to note the effect of using topical cortisone on the face? } \\
\hline Yes & 77 & $27.6 \%$ \\
\hline No & 202 & $72.4 \%$ \\
\hline \multicolumn{3}{|l|}{ Had any side effects from using topical cortisone? } \\
\hline Yes & 46 & $16.5 \%$ \\
\hline No & 233 & $83.5 \%$ \\
\hline \multicolumn{3}{|l|}{ If yes, what were these side effects? $(n=46)$} \\
\hline Peeling & 24 & $52.2 \%$ \\
\hline Redness & 19 & $41.3 \%$ \\
\hline Dryness & 11 & $23.9 \%$ \\
\hline Skin color change & 10 & $21.7 \%$ \\
\hline Irritation & 9 & $19.6 \%$ \\
\hline Acne-like rash & 5 & $10.9 \%$ \\
\hline Itching & 5 & $10.9 \%$ \\
\hline Burning sensation & 3 & $6.5 \%$ \\
\hline Skin stretch marks & 1 & $2.2 \%$ \\
\hline \multicolumn{3}{|c|}{ Did you know the side effects of using topical corticosteroids? } \\
\hline Yes & 108 & $38.7 \%$ \\
\hline No & 171 & $61.3 \%$ \\
\hline \multicolumn{3}{|c|}{ Will you return to using cortisone if your side effects improve? $(n=46)$} \\
\hline Yes & 23 & $50.0 \%$ \\
\hline No & 23 & $50.0 \%$ \\
\hline
\end{tabular}

A total of 93 (33.3\%) users were not satisfied, 78 (28\%) were moderately satisfied, and $108(38.7 \%)$ TCs users were highly satisfied. A total of $127(68.3 \%)$ steroid users needed less than 1 month to be satisfied, while 39 (21\%) needed $1-3$ months, but $5(2.7 \%)$ needed more than 9 months. A total of 167 (59.9\%) participants did not use anything after they stopped using TCs, while 53 (19\%) used another type of cream, and 50 (17.9\%) used other methods. As for participants' observations on their skin after stopping TCs use, 161 (65.7\%) observed no change in the treatment result, $65(26.5 \%)$ still had the same problem as before using cortisone, and 12 (4.9\%) had persistent side effects (Table 3 ).

A total of $54.5 \%$ of participants aged less than 20 years used TCs, compared to $30.5 \%$ of those aged 50 years or more with recorded statistical significance $(p=0.001)$. Moreover, TCs use was recorded among $47.8 \%$ of females, in comparison with $36.8 \%$ of males $(p=0.031)$. A total of $51.7 \%$ of the students used facial TCs versus $35.4 \%$ of workers at non-governmental settings $(p=0.029)$. Furthermore, facial TCs use was reported among $77.3 \%$ of nurses, compared to $43.5 \%$ of physicians ( $p=0.027$ ) (Table 4$)$. 
Table 3. Distribution of participants' satisfaction regarding topical steroid use.

\begin{tabular}{|c|c|c|}
\hline Satisfaction Regarding Topical Steroid Use & No (279) & $\%$ \\
\hline \multicolumn{3}{|c|}{ How satisfied are you with the results of topical cortisone on the face? } \\
\hline Not satisfied (1-4) & 93 & $33.3 \%$ \\
\hline Moderate satisfaction (5-7) & 78 & $28.0 \%$ \\
\hline High satisfaction $(8-10)$ & 108 & $38.7 \%$ \\
\hline \multicolumn{3}{|l|}{ Duration until a high satisfaction level } \\
\hline$<1$ month & 127 & $68.3 \%$ \\
\hline $1-3$ months & 39 & $21.0 \%$ \\
\hline $3-6$ months & 7 & $3.8 \%$ \\
\hline 6-9 months & 8 & $4.3 \%$ \\
\hline$>9$ months & 5 & $2.7 \%$ \\
\hline \multicolumn{3}{|c|}{ If you have stopped using topical corticosteroids on the face, what have you done after stopping? } \\
\hline Used another type of cream & 53 & $19.0 \%$ \\
\hline I went to a dermatologist for side effects & 9 & $3.2 \%$ \\
\hline Others & 50 & $17.9 \%$ \\
\hline I did not use anything & 167 & $59.9 \%$ \\
\hline \multicolumn{3}{|c|}{ Observations on your skin after stopping topical cortisone use? } \\
\hline Persistent side effects & 12 & $4.9 \%$ \\
\hline Worsening side effects & 7 & $2.9 \%$ \\
\hline $\begin{array}{l}\text { Still have the problem present before using } \\
\text { cortisone }\end{array}$ & 65 & $26.5 \%$ \\
\hline No change in the treatment result & 161 & $65.7 \%$ \\
\hline
\end{tabular}

Table 4. Distribution of participants use of topical facial corticosteroids by their personal data.

\begin{tabular}{|c|c|c|c|c|c|c|}
\hline \multirow{3}{*}{ Personal Data } & \multirow{3}{*}{$\begin{array}{c}\text { Total } \\
\text { No }(\%)\end{array}$} & \multicolumn{4}{|c|}{ Use of Topical Corticosteroids on Face } & \multirow{3}{*}{$p$-Value } \\
\hline & & \multicolumn{2}{|c|}{ Yes } & \multicolumn{2}{|c|}{ No } & \\
\hline & & No & $\%$ & No & $\%$ & \\
\hline \multicolumn{7}{|l|}{ Age in years } \\
\hline$<20$ & $112(18.3 \%)$ & 61 & $54.5 \%$ & 51 & $45.5 \%$ & \\
\hline $20-29$ & $282(46.2 \%)$ & 144 & $51.1 \%$ & 138 & $48.9 \%$ & 0.001 \\
\hline $30-49$ & $158(25.9 \%)$ & 56 & $35.4 \%$ & 102 & $64.6 \%$ & \\
\hline $50+$ & $59(9.7 \%)$ & 18 & $30.5 \%$ & 41 & $69.5 \%$ & \\
\hline \multicolumn{7}{|l|}{ Gender } \\
\hline Male & $117(19.1 \%)$ & 43 & $36.8 \%$ & 74 & $63.2 \%$ & 0.031 \\
\hline Female & $494(80.9 \%)$ & 236 & $47.8 \%$ & 258 & $52.2 \%$ & \\
\hline \multicolumn{7}{|l|}{ Educational level } \\
\hline $\begin{array}{l}\text { Below high } \\
\text { school }\end{array}$ & $23(3.8 \%)$ & 9 & $39.1 \%$ & 14 & $60.9 \%$ & 0.115 \\
\hline High school & $187(30.6 \%)$ & 97 & $51.9 \%$ & 90 & $48.1 \%$ & \\
\hline University/above & $401(65.6 \%)$ & 173 & $43.1 \%$ & 228 & $56.9 \%$ & \\
\hline \multicolumn{7}{|c|}{ Are you a health care worker? } \\
\hline Physician & $62(13.7 \%)$ & 27 & $43.5 \%$ & 35 & $56.5 \%$ & \\
\hline Pharmacist & $9(2.0 \%)$ & 4 & $44.4 \%$ & 5 & $55.6 \%$ & 0.027 \\
\hline Nurse & $22(4.9 \%)$ & 17 & $77.3 \%$ & 5 & $22.7 \%$ & \\
\hline No & $358(79.4 \%)$ & 159 & $44.4 \%$ & 199 & $55.6 \%$ & \\
\hline
\end{tabular}

\section{Discussion}

Corticosteroids are a type of anti-inflammatory drug that can be prescribed in a systemic or topical form. In 1951, topical corticosteroids (TCs) were used for the first time by American dermatologist Marion Baldur Sulzberger [2]. In modern dermatological practice, TCs have become one of the most widely used treatment methods [3].

Regarding the prevalence of using facial TCs among the Saudi population, this study shows that 279 (45\%) participants used facial topical steroids, while 332 (54\%) did not use 
facial topical steroids. Topical steroids usage is more popular among females than the male population, which is similar to what was reported in previous studies [6,8]. Most of our participants were university graduates or below high school education level. The most used TCs in this study was Mometasone furoate $0.1 \%$ cream $(18.2 \%)$, followed by Fusidic acid/betamethasone cream (16.7\%), Hydrocortisone $1 \%$ cream $(4.4 \%)$, and Betamethasone valerate $0.1 \%$ cream $(0.8 \%)$. This is similar to the result: mid potent formulation (mometasone) was the most common overused TCs [6]. This can be explained by the ever-increasing popularity of triple combinations (mometasone, hydroquinone, and tretinoin) for fairness creams [6].

The most common reason for participants to use facial TCs in this study was treating acne $(45.9 \%)$. This can be explained by the fact that acne vulgaris is one of the most common inflammatory disorders, affecting a large percentage of the young population in Saudi Arabia (78\%) [9]. In a similar study conducted in India, the most common indication of topical steroids was skin lightening (70.6\%), followed by treating acne (12.9\%) [6]. Locally, the study conducted in Hail, Saudi Arabia, had shown that the most common reason for using topical steroids was skin lightening [3].

In this study, the most commonly used form of TCs was ointment in a frequency of once daily for more than nine months, while the average duration in a previous, similar study was around $6 \pm 2$ months [6]. However, in another study conducted in Hail, the majority of participants (67\%) used TCs for less than three months [10].

This study exhibits that $55.2 \%$ of the users had facial topical steroids based on doctor prescriptions. This matched the results of another study: $44 \%$ of women who used the topical steroids received the prescription from a doctor [10]. Among those who used unprescribed topical steroids, family and friends were the main sources of advice, similar to the other local study, which revealed that the leading inspirations toward the usage of facial TCs were relatives and friends [3,5].

Because the nature of facial skin is thinner than other parts of the body, with a high transcutaneous absorption rate, side effects are more common on the face [3]. Nevertheless, only $16.5 \%$ of the participants of this study report any side effects of using TCs. This could be related to prescription restrictions in the kingdom, which participates in limiting TCs misuse. However, our study reveals some side effects, including peeling (52.2\%), redness, dryness, skin color change, irritation, acne-like rash, and itching. New-onset acne or exacerbation of preexisting acne represented the single most important adverse event. This was followed by erythema/telangiectasia [6]. Among our participants, $61.3 \%$ were unaware of the side effects of using TCs, while in the Indian study, $83.76 \%$ were unaware of the side effects of the TCs [5]. Exactly 50\% of those with side effects reported their willingness to reuse cortisone if the side effects improved.

Regarding the satisfaction of TCs use, 38.7\% were highly satisfied. Most patients $(68.3 \%)$ needed less than one month to be satisfied. The majority of our participants (59.9\%) did not use anything after they stopped using TCs. However, only a few (3.2\%) went to a dermatologist for side effects. The observations on the skin after stopping TCs, $65.7 \%$ observed no change in the treatment result.

\section{Conclusions}

The usage of facial TCs among the Saudi population is not uncommon. Topical facial steroids side effects are not very common in Saudi Arabia (16.5\%). A large population are not aware of the side effects of unsupervised usage of TCs. Efforts should be made to increase awareness about the adverse effects of topical TCs.

Author Contributions: All authors of this study were equally involved in the design, data collection, analysis, drafting and correction of the final draft, and the author was responsible for the proper implementation of the study at all stages. There is no author whose name is not listed in the authors list. All authors have read and agreed to the published version of the manuscript.

Funding: The study did not receive any external funding. 
Institutional Review Board Statement: IRB approval was obtained from the scientific research and ethical committee of King Fahad Hospital Hofuf, number 50-EP-2021.

Informed Consent Statement: Informed consent was obtained electronically from all individual participants included in the study.

Data Availability Statement: All data associated with this study are available and will be provided upon editor's request.

Conflicts of Interest: The authors declare that there is no conflict of interest.

Ethical Approval: The study was approved by the King Fahad Hospital-Hofuf (ethical approval code: 50-EP-2021).

\section{References}

1. Burns, C.M. The history of cortisone discovery and development. Rheum. Dis. Clin. N. Am. 2016, 42, 1-14. [CrossRef]

2. Abraham, A.; Roga, G. Topical steroid-damaged skin. Indian J. Dermatol. 2014, 59, 456-459. [CrossRef] [PubMed]

3. Ansari, M.; Palaian, S.; Ibrahim, M.I.M.; Shankar, P.R. The use of topical clobetasol among the women in hail region, Saudi Arabia: A cross-sectional study on knowledge and practice. J. Pharm. Res. Int. 2019, 31, 1-7. [CrossRef]

4. Saraswat, A.; Lahiri, K.; Chatterjee, M.; Barua, S.; Coondoo, A.; Mittal, A.; Panda, S.; Rajagopalan, M.; Sharma, R.; Abraham, A.; et al. Topical corticosteroid abuse on the face: A prospective, multicenter study of dermatology outpatients. Indian J. Dermatol. Venereol. Leprol. 2011, 77, 160-166. [CrossRef]

5. Biswas, P.; Pal, D.; Das, S.; De, A.; Sharma, N.; Ansari, A. Topical steroid damaged/dependent face (TSDF): A study from a tertiary care hospital in Eastern India. Indian J. Dermatol. 2018, 63, 375-379. [CrossRef]

6. Jain, S.; Mohapatra, L.; Mohanty, P.; Jena, S.; Behera, B. Study of clinical profile of patients presenting with topical steroid-induced facial dermatosis to a tertiary care hospital. Indian Dermatol. Online J. 2020, 11, 208.

7. Population Estimates [Internet]. General Authority for Statistics. 2021. Available online: https://www.stats.gov.sa/en/43 (accessed on 12 April 2021).

8. Sendrasoa, F.A.; Ranaivo, I.M.; Andrianarison, M.; Raharolahy, O.; Razanakoto, N.H.; Ramarozatovo, L.S.; Rabenja, F.R. Misuse of topical corticosteroids for cosmetic purpose in Antananarivo, Madagascar. BioMed Res. Int. 2017, 2017, 9637083. [CrossRef]

9. Alanazi, T.M.; Alajroush, W.; Alharthi, R.M.; Alshalhoub, M.Z.; Alshehri, M.A. Prevalence of acne vulgaris, its contributing factors, and treatment satisfaction among the saudi population in Riyadh, Saudi Arabia: A cross-sectional study. J. Dermatol. Dermatol. Surg. 2020, 24, 33. [CrossRef]

10. AlAfnan, S.S.; Alhussaini, S.A.; Alshammarie, A.A.; Alshammari, R.S.; Elagib, H.M. Misuse of topical corticosteroids in women in Hail region Saudi Arabia. Int. J. Community Med. Public Health 2019, 6, 1880-1885. [CrossRef] 